\title{
CARINAL RECONSTRUCTION WITH A Y-SHAPED COLLAGEN-CONJUGATED PROSTHESIS
}

Takashi Sekine, MD

Tatsuo Nakamura, MD

Kazuya Matsumoto, MD

Yu Liu, MD

Hiroki Ueda, MastEng

Nobuyuki Tamura, MD

Yasuhiko Shimizu, MD
Background: Carinal reconstruction by direct suturing is associated with a high mortality because high tension at the anastomosis can lead to tracheobronchial fistula. A new tracheal prosthesis was therefore designed for reconstruction of the tracheal bifurcation and applied for experimental carinal replacement in dogs.

Methods: The main frame of the new prosthesis consists of a Y-shaped Marlex mesh tube (C.R. Bard, Inc, Billerica, Mass) reinforced with polypropylene spirals, to which collagen extracted from porcine skin is chemically conjugated to provide biocompatibility and airtightness. This conjugated collagen is composed of amorphous and sponge collagen layers. The tracheobronchial bifurcation was replaced with the prosthesis in 10 beagle dogs.

Results: Eight dogs survived the postoperative period, and 2 dogs died within 4 days after the operation. Bronchoscopic examination revealed that the tracheal prosthesis was covered with smooth whitish tissue and that no stenosis or dehiscence was present in the 8 dogs even 6 months after the operation. Slight mesh exposure was recognized in $1 \mathrm{dog}$. Histologic examination revealed that approximately one half of the luminal surface was covered with ciliated columnar epithelium or nonciliated squamous epithelium. In the remaining lumen, especially in the middle portion of the prosthesis, connective tissue without epithelium was observed.

Conclusions: These long-term results indicate that our bifurcated tracheal prosthesis can be used for reconstruction of the tracheobronchial bifurcation with long-term safety. (J Thorac Cardiovasc Surg 2000;119:1162-8)
$\mathrm{T}_{\mathrm{c}}^{\mathrm{h}}$ he standard method of tracheal reconstruction in a clinical setting is end-to-end anastomosis. However, if the resected segment is more than $6 \mathrm{~cm}$ long, high tension is concentrated at the sites of anastomosis and can sometimes cause severe and fatal postoperative complications such as dehiscence. ${ }^{1}$ Stomal construction with skin flaps has occasionally been adopted when

From the Department of Bioartificial Organs, Institute for Frontier Medical Sciences, Kyoto University, Sakyo-ku, Kyoto, Japan.

This work was supported in part by a research grant (JSPSRFTF96100203).

Received for publication Dec 20, 1999; revisions requested Jan 24, 2000; revisions received Feb 14, 2000; accepted for publication Feb 16, 2000.

Address for reprints: Takashi Sekine, MD, Department of Bioartificial Organs, Institute for Frontier Medical Sciences, Kyoto University, 53 Kawahara-cho, Shogoin, Sakyo-ku, Kyoto 606-8397, Japan (E-mail: sekine @ frontier.kyoto-u.ac.jp).

Copyright $\odot 2000$ by The American Association for Thoracic Surgery

$0022-5223 / 2000 \$ 12.00+0 \quad \mathbf{1 2 / 1 / 1 0 6 6 5 2}$

doi: $10.1067 / \mathrm{mtc} .2000 .106652$ larger tracheal segments have been resected. ${ }^{2}$ However, this method can only be applied to the cervical trachea. Accordingly, many types of artificial trachea have been designed and assessed, but so far none of them has been satisfactory for clinical use.

We have developed a new type of tracheal prosthesis composed of a porous frame and porcine collagen and have already reported that a straight version of the prosthesis can be applied safely for circumferential replacement of the cervical and thoracic trachea in animal experiments. ${ }^{3,4}$

When the carina is affected by a disease such as cancer, removal of the lesion and direct anastomosis is attempted to reconstruct the airway. ${ }^{5}$ However, the surgical procedure for carinal reconstruction by direct anastomosis is usually very complicated because of difficulties with maintenance of anesthesia. Also, the postoperative mortality is still very high because of high tension and poor vascularity at the suture lines. ${ }^{6,7}$ Therefore, carinal reconstruction is considered to be one of the most difficult of pulmonary operations. ${ }^{8,9}$ In 


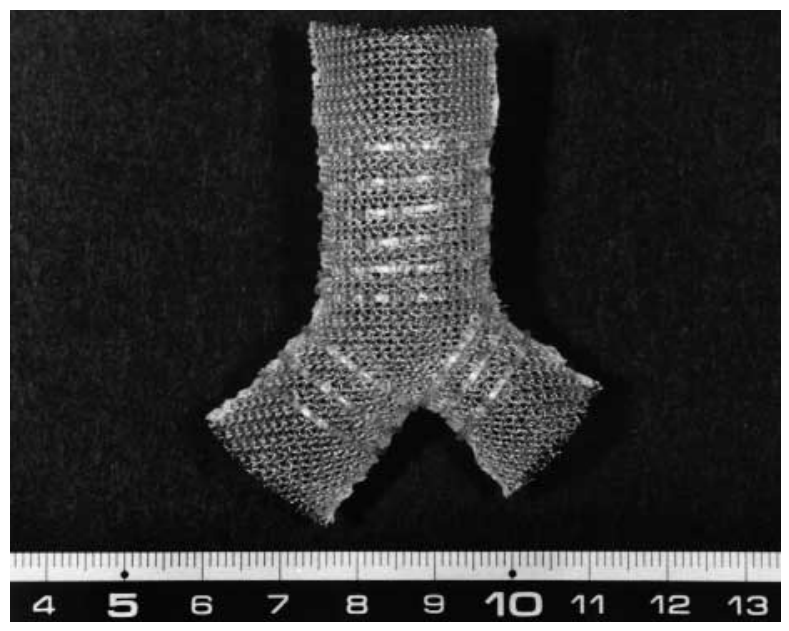

Fig 1. Y-shaped prosthesis made of Marlex mesh and polypropylene spirals.

this situation, a bifurcated type of tracheal prosthesis is clinically necessary for reducing the tension at the suture lines.

We recently produced a carina-type prosthesis and used it for experimental carinal replacement in dogs. ${ }^{10}$ Good long-term results were obtained in the surviving dogs, but at the same time a relatively high number of postoperative deaths occurred. One of the reasons for these postoperative deaths was air leakage from the trunk of the prosthesis. Therefore, in the present study, we refined the Y-shaped prosthesis to obtain better postoperative results and evaluated its long-term safety for carinal replacement in dogs.

\section{Materials and methods}

Prosthesis. A Y-shaped tube was formed with two sheets of Y-shaped polypropylene mesh with a pore size of $260 \mu \mathrm{m}$ (Marlex mesh, C.R. Bard, Inc, Billerica, Mass) by melting the edges together and shaping them in a metal mold. The main body and two branches of the tube were then reinforced with a polypropylene spiral (1 $\mathrm{mm}$ in diameter) (Fig 1). The spiral was attached to the external surface of the mesh tube by thermal melt-bonding at 5-mm intervals and further fixed with 60 Prolene sutures (Ethicon, Inc, Somerville, NJ). The polypropylene spirals provided the tube with stiffness against compression. Collagen conjugation process was then performed with porcine dermal atelocollagen (supplied by Nippon Meatpackers Inc, Ibaraki, Japan), consisting of type 1 (70\%-80\%) and type 3 collagen dissolved in hydrochloric acid solution, $\mathrm{pH} 3.0$, at a concentration of $1.2 \%$. The collagen was immobilized on the surface of the tube after exposure of the mesh to a coronal discharge at $9 \mathrm{kV}$ for 10 minutes to activate the polymer surface. The prosthesis was then coated 15 times with the collagen solution. It was placed in a Teflon mold that had the same Y shape but was slightly larger than
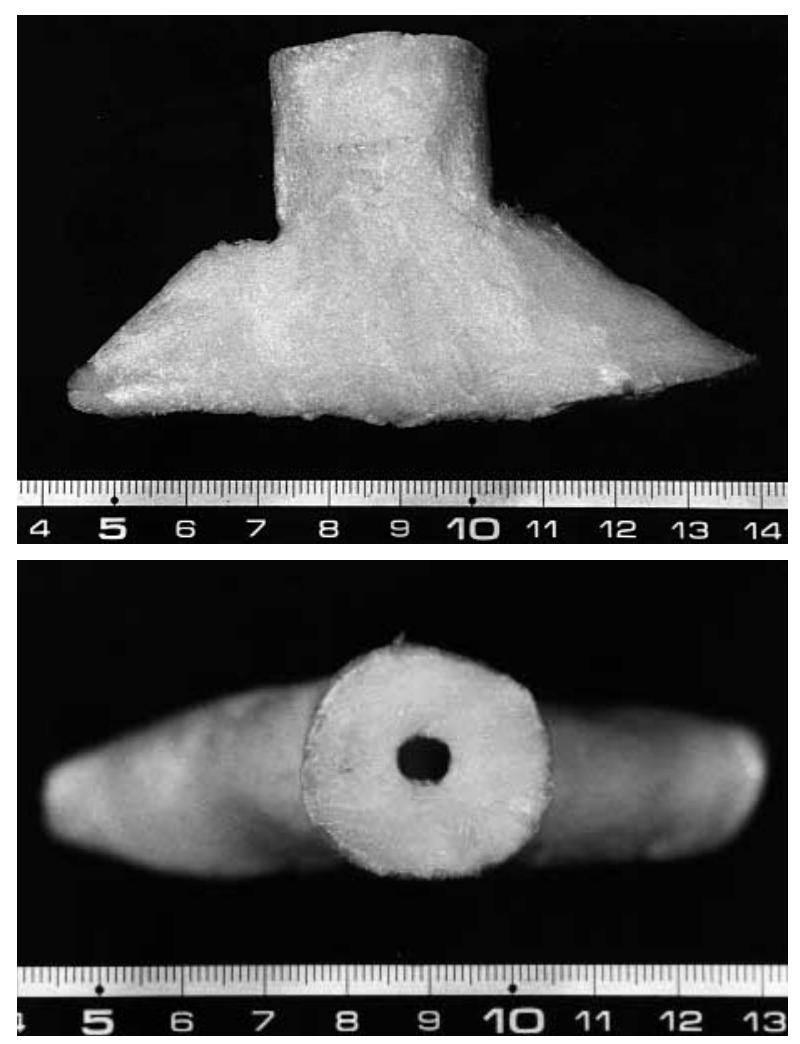

Fig 2. Top, Y-shaped prosthesis after collagen conjugation. Bottom, upper view.

the prosthesis, with an inner diameter of $37 \mathrm{~mm}$. At the same time, a 6-mm tube was inserted into the center of the prosthesis with its axis parallel to the lumen. The collagen solution, which had been stirred at $8000 \mathrm{rpm}$ for 15 minutes, was poured into the space between the outer mold and the inner tube and then freeze-dried. In this process the collagen became a porous spongelike structure with a pore size range of 100 to $500 \mu \mathrm{m}$. Finally, the prosthesis was heated at $140^{\circ} \mathrm{C}$ in a vacuum for 24 hours to induce cross-linking between the collagen molecules, so that the collagen would be stable in vivo. All of these processes made the prosthesis biocompatible and airtight (Fig 2).

Animal experiments. Operations were performed with general anesthesia on 10 beagle dogs weighing between 9 and $13 \mathrm{~kg}$. A mid abdominal incision was made with the animal in a supine position, and the spleen was resected to mobilize a flap of the omentum. The omental flap was introduced into the right thoracic cavity through a slit in the right hemidiaphragm. After the abdominal incision had been closed, a right thoracotomy was performed with the animal in the left lateral recumbent position. The azygos vein was cut after ligation, and the tracheobronchial bifurcation was exposed. First, the left main bronchus was cut $8 \mathrm{~mm}$ from the bifurcation, and the central cut end was temporarily made airtight with over-and-over sutures to maintain ventilation. The prosthesis and the distal cut end of the left main bronchus were 


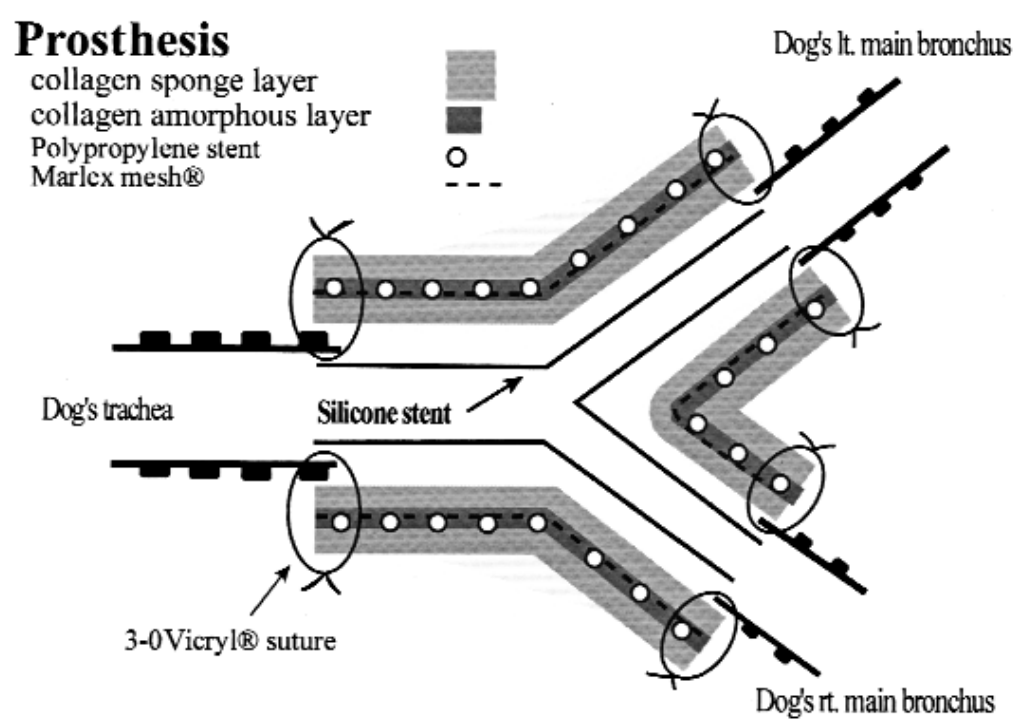

Fig 3. Method of carinal reconstruction: A Y-shaped silicone stent has been inserted into the prosthesis during the operation.

Table I. Experimental results of carinal reconstruction with a tracheal prosthesis

\begin{tabular}{lccccc}
\hline Dog No. & Prognosis & Survival $(\mathrm{mo})$ & Mesh exposure & Epithelialization (\%) & Complications \\
\hline 1 & Killed & 10 & None & 80 & - \\
2 & Died, unknown cause & 4 days & & & Lung abscess \\
3 & Killed & 11 & None & 40 & - \\
4 & Killed & 11 & None & 60 & - \\
5 & Killed & 11 & Small $\left(7 \times 2 \mathrm{~mm}^{2}\right)$ & 30 & - \\
6 & Killed & 8 & None & 60 & - \\
7 & Killed & 9 & None & 40 & - \\
8 & Died, bronchial fistula & 3 days & None & 40 & - \\
9 & Killed & 10 & None & & - \\
\hline
\end{tabular}

anastomosed with 3-0 Vicryl (Ethicon) interrupted sutures, the cut end of the bronchial stump being inserted into the prosthesis lumen. The trachea was then cut about $5 \mathrm{~cm}$ from the carina, and a sterile flexible intubation tube was inserted into the cut end of the central trachea to maintain ventilation. The oral cut end of the trachea was anastomosed to the prosthesis in the same manner as the left main bronchus. For the third step, respiration was again switched to transoral intubation, and anastomosis of the right main bronchus was performed. During this procedure the transoral intubation tube was placed in the native trachea, because if the intubation tube were to advance into the left main bronchus through the prosthesis, it might break or damage the prosthesis. During anastomosis of the right main bronchus, the open end of the prosthesis was repeatedly sealed with the surgeon's finger to maintain respiration. The resected carinal bifurcation included six tracheal rings, one ring of the right main bronchus, and two rings of the left main bronchus.

During the operation the prosthesis was preclotted with 5 $\mathrm{mL}$ of blood with the intent of supplying some growth factors that accelerate the tissue regrowth. As a result, the spongelike collagen layer inside and outside of the lumen will shrink in volume. Then a Y-shaped silicone stent was inserted into the prosthesis lumen. This stent, which was not fixed with sutures, was intended to promote secretory transport until the prosthesis had become covered with host tissue and to protect the prosthesis from local infection and dissolution of the collagen coating by secretion. During the replacement procedures, the prosthesis was covered with a silicone sheet to prevent loss of the collagen coating. This sheet was fixed with 4-0 nylon sutures and removed before omentopexy of the prosthesis. The inserted inner silicone stent, on the other hand, was removed 8 weeks after the operation with the use of bronchofiberscopic forceps (Fig 3). After completion of the anastomosis, fibrin glue (Beriprast-P, Hoechst Marion Roussel Ltd, Bridgewater, NJ) was applied to prevent air leakage from the needle holes in the prosthesis. The prosthesis was then wrapped with an omental pedicle. Before the wound was closed, a chest tube was placed in the right hemithorax for aspiration at a negative pressure of $10 \mathrm{~cm}$ 


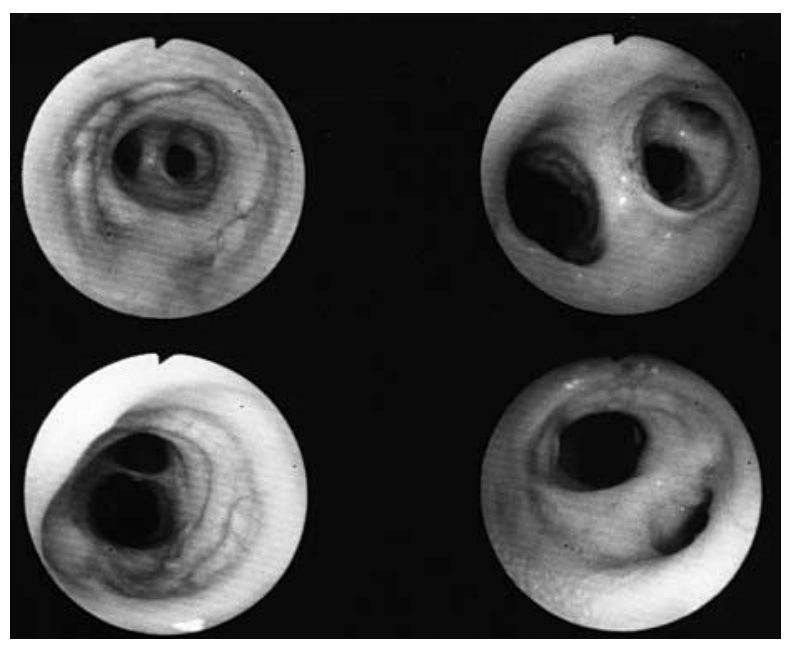

Fig 4. Bronchoscopic views 10 months after the operation. Neither stenosis nor granulation at the site of anastomosis with the trachea (upper left), left main bronchus (lower left), or right main bronchus (lower right) is evident. Complete covering of the mesh by regenerated tissue is observed in the region of the bifurcation (upper right).

$\mathrm{H}_{2} \mathrm{O}$ for about 30 minutes. After cessation of major air leakage had been confirmed, the chest tube was removed. A 1000$\mathrm{mg}$ dose of ampicillin was injected intramuscularly on the day of the operation, and a 500-mg dose was administered orally every day for 2 months until the silicone stent in the prosthesis had been extracted. Bronchial cleaning with a fiberscope was only performed immediately after the operation on the day of the operation. No additional care other than routine management was provided for the animals.

Bronchoscopic and histologic examinations. Bronchoscopic examination was performed periodically with the animal under general anesthesia. The luminal surface of the prosthesis was examined with a bronchofiberscope (model BF1T20, Olympus Optical Co Ltd, Tokyo, Japan).

Dogs were put to death with an injected overdose of sodium pentobarbital at intervals of 8 to 11 months for light microscopic and scanning electron microscopic examinations. The epithelial cells were checked for cilia with a scanning electron microscope (S-450, Hitachi Ltd, Tokyo, Japan). All of the surgical and euthanasia procedures were performed in accordance with the "Guide for the Care and Use of Laboratory Animals" published by the National Institutes of Health (NIH Publication No. 85-23, revised 1985).

\section{Results}

We attempted carinal replacement in $10 \mathrm{dogs}$, and the results are summarized in Table I. Bronchoscopic examinations performed periodically revealed neither stenosis nor granulation in the region of the anastomosis in all 8 dogs examined (Fig 4). The luminal surface

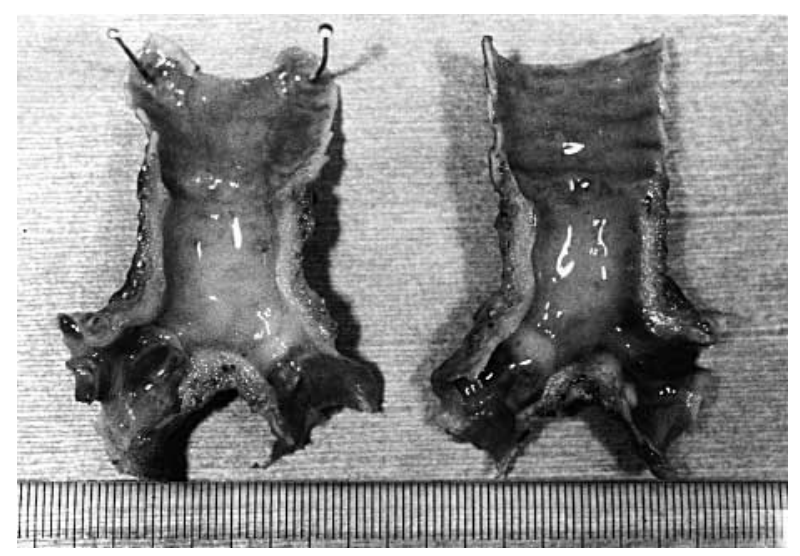

Fig 5. Longitudinal section of the prosthesis 10 months after the operation. Longitudinal sections in all the surviving animals showed that the luminal surface was covered by smooth, whitish tissue.

of the implanted prosthesis appeared shiny and whitish, suggesting complete coverage of the lumen by regenerated tissue. No mesh exposure was recognized even in the middle of the prosthesis, including the carinal bifurcation, except in $1 \operatorname{dog}(\operatorname{dog} 5)$, in which slight mesh exposure, about $7 \times 2 \mathrm{~mm}^{2}$, was observed at the center of the carina. Despite this mesh exposure, the dog was asymptomatic and its general condition was good. No retention of sputum was observed in the lumen of the prosthesis, except in $1 \mathrm{dog}(\operatorname{dog} 3)$ that had an abscess in the right lung. In this dog, secretions from the right upper bronchus and slight loss of body weight (10.0$9.5 \mathrm{~kg}$ ) were recognized. All the other surviving dogs gained weight during the postoperative period.

Histologic examinations. In longitudinal section, the surface of the prosthesis lumen was covered by smooth whitish tissue continuous with the native respiratory epithelium (Fig 5). A small area of mesh exposure $\left(7 \times 2 \mathrm{~mm}^{2}\right)$ could be seen at the center of the carina in dog 5 without any sign of local infection. In the other dogs no mesh exposure was recognized. No granulation tissue formation was detected in the lumen. Examination with a light microscope revealed that the epithelium had grown over the prosthesis. The lining of regenerated epithelium was smoothly continuous with the native trachea. The Marlex mesh and polypropylene spiral had become buried in connective tissue. From $30 \%$ to $80 \%$ of the lumen was covered by tracheal epithelium (Table I). Ciliated columnar epithelial cells predominated near the sites of anastomosis and nonciliated squamous cells predominated in the middle portion (Fig 6). Tracheal epithelium was not detected over 

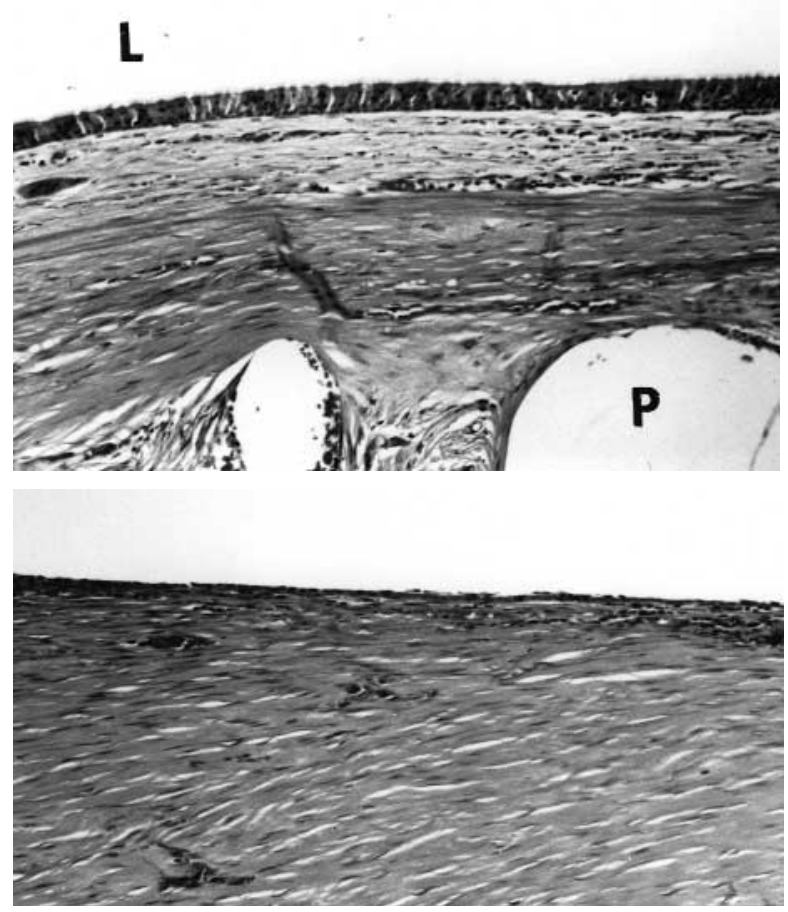

Fig 6. Photomicrograph of a prosthesis removed 10 months after implantation. Ciliated epithelial cells line the prosthesis near the anastomosis (top), but squamous epithelial cells predominate in the middle portion of the prosthesis (bottom). (Hematoxylin and eosin stain; original magnification $\times 100$.) $L$, Tracheal lumen; $P$, polypropylene mesh.

the regenerated connective tissue seen mainly in the middle portion of the prosthesis. Scanning electron microscopy showed that the lumen near the anastomosis was covered with ciliated epithelial cells. In the middle portion, however, the ciliated epithelial cells were surrounded by cells bearing short microvilli (Fig 7). Areas of connective tissue without epithelium were also observed in some parts.

\section{Discussion}

Carinal reconstruction by direct suturing is sometimes attempted clinically when the carina is affected by neoplasm. However, among the various methods of bronchopulmonary surgery, this procedure is associated with a significant mortality. One of the reasons is postoperative tracheobronchial fistula caused by high tension at the anastomosis site. The maximum permissible length of tracheal resection for direct suturing is reported to be approximately $6.5 \mathrm{~cm}$. However, for carinal resection the situation is more complicated, and there are no fixed criteria for possible resection length.
Therefore, a Y-shaped prosthesis has been sought for carinal reconstruction to avoid high tension at the anastomosis.

Many types of materials have been examined for use in tracheal prostheses. ${ }^{11-13}$ The prosthesis devised by Neville, Bolanowski, and Koita, ${ }^{14}$ which is made of silicone rubber with terminal Dacron rings, had been used clinically. It is nonporous and, hence, re-epithelialization along the lumen cannot be expected. During longterm observation, formation of granulation tissue or dehiscence occurred at the interface between the prosthesis and the recipient tissue. ${ }^{15}$ Furthermore, hemorrhage resulting from tissue erosion by the prosthesis has been reported. ${ }^{16}$

For a number of years, we have been trying to develop porous tracheal prostheses and have conducted animal experiments with straight prostheses. The porous type of prosthesis induces tissue invasion into the mesh, thus assisting re-epithelialization of the lumen and helping to avoid the formation of granulation tissue and dehiscence at the interface between the prosthesis and the host tissue. As a porous material, soft Marlex mesh was used because heavy Marlex mesh has been reported to cause massive bleeding from the adjacent innominate artery. ${ }^{17}$ At the same time, the pore size of the soft Marlex mesh, which is approximately $300 \mu \mathrm{m}$, has already been shown to be optimal for invasion of tracheal tissue into the mesh. ${ }^{18}$ On the other hand, soft Marlex mesh has its own inherent problem of deformation when slightly compressed from the outside. Therefore, reinforcement by polypropylene spirals around the mesh is needed to prevent this. Another problem with the porous-type prosthesis is insufficient air-sealing. Poticha and Lewis ${ }^{19}$ and Jacobs ${ }^{20}$ reported a 2-stage operation for ensuring the airtightness and tissue affinity of a porous tracheal prosthesis. They induced tissue invasion into the prosthesis by burying it under a percutaneous tissue pocket. After tissue had invaded the mesh, it was transplanted for tracheal reconstruction. This method, however, is too complicated for clinical use.

Chemically conjugated collagen on the porous prosthesis solves this problem and prevents air leakage from the mesh during the early postoperative period. Also, tissue invasion into the mesh can be accomplished before the collagen is resorbed from the prosthesis. Omentopexy was adopted because lack of vascularity around the anastomosis is considered to cause dehiscence. ${ }^{21}$ Our previous experiment revealed that placement of an omental pedicle around the prosthesis enhanced revascularization into the mesh, especially in the first few months after surgery. ${ }^{4}$ 
Collagen is used in our prosthesis not only for air sealing but also for enhancement of tissue invasion. Collagens, the elements of the extracellular matrix, have been reported to play a role in cell transformation, division, proliferation, and detachment. ${ }^{22,23}$ The collagen we used is made up of type 1 (70\%-80\%) and type 3 collagen. Type 1 collagen is reported to promote the differentiation of ciliated epithelium, ${ }^{24}$ and our previous experiments showed that collagen in the above ratio provided the most suitable conditions for tissue invasion. With regard to the fate of porcine collagen, we speculate that it was replaced by the native collagen in the first postoperative few weeks. This has been examined in esophageal replacement with the same materials. $^{25}$

In a previous experiment ${ }^{10}$ we had produced a Yshaped prosthesis with the same structure as our straight type of prosthesis. That prosthesis was made of Marlex mesh, a polypropylene spiral, and an amorphous collagen layer. When used to repair tracheal defects in dogs, 13 out of 20 animals died within 11 days after the operation. One of the reasons for these early postoperative deaths was air leakage from the trunk of the prosthesis. This leakage was suspected to have occurred at a break point between the mesh and the polypropylene caused by compression stress imposed on the prosthesis during the surgical procedures. At the same time, excessively rapid resorption of the collagen from the prosthesis may have caused a delay or lack of tissue invasion into the mesh, thereby resulting in air leakage.

In the present study, we improved the amount and structure of the collagen on the prosthesis. The amount of collagen was increased by introducing a collagen sponge layer ${ }^{26,27}$ over the amorphous collagen layer, and cross-linking between the collagen molecules was induced by heat to ensure that the prosthesis retained the collagen for a longer period. To prevent loss of collagen volume during the replacement procedures, we covered the prosthesis with a silicone sheet, which also prevented breakage at the attachment point between the polypropylene stent and the collagen. In addition to this covering, a Y-shaped silicone stent was inserted into the prosthesis to protect the collagen on the prosthesis lumen from infection and dissolution by respiratory secretions. These improvements appeared to have prevented air leakage from the trunk of the prosthesis during the early postoperative period.

We found that not all of the prosthesis lumen was re-epithelialized (Table I). Confluent epithelialization was observed in only $1 \mathrm{dog}$. At the site of anastomosis, a continuous covering of ciliated epithelium
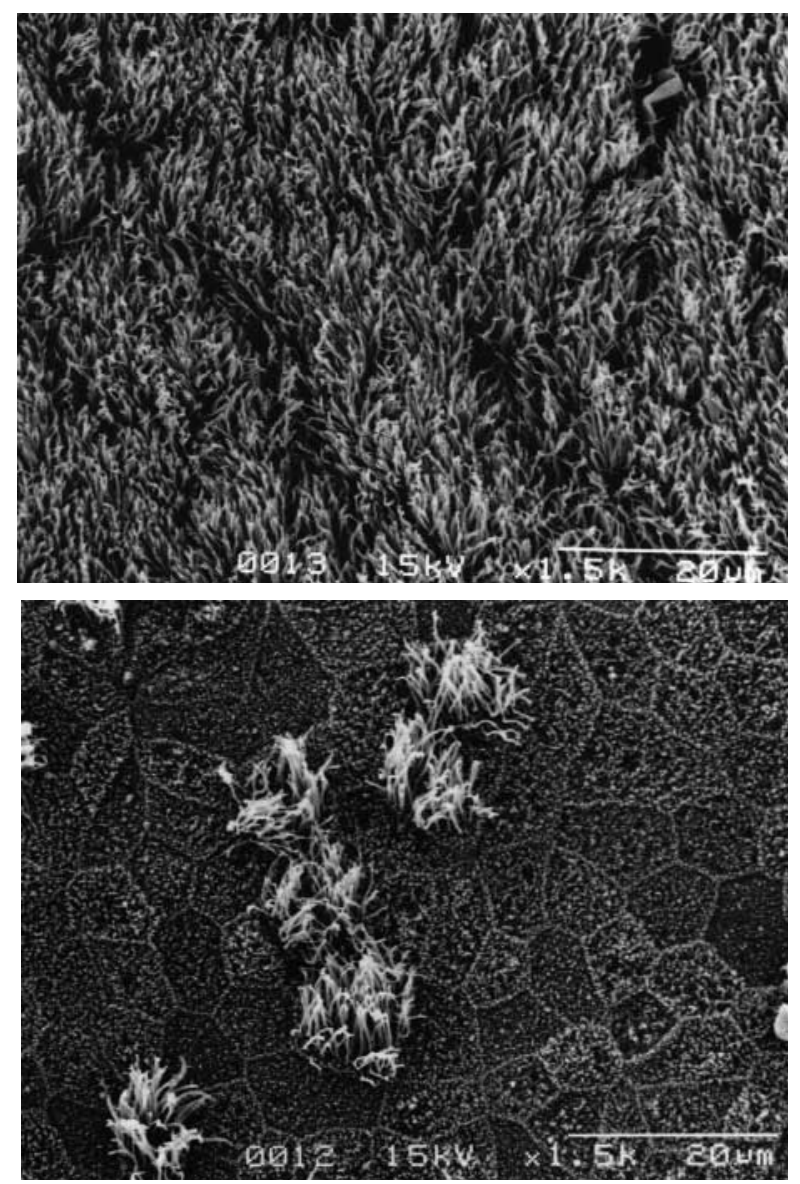

Fig 7. Scanning electron micrographs of the luminal surface. The surface is covered by ciliated epithelial cells (top), but in the middle of the prosthesis a few ciliated epithelial cells are surrounded by cells with short microvilli (bottom).

was observed to extend from the native trachea over the luminal surface. Over the prosthesis lumen, ciliated epithelium showed gradual transition into nonciliated squamous epithelium, and an area of connective tissue without epithelium was observed in the middle portion of the prosthesis. However, central stenosis due to formation of granulation tissue was not observed in any of the dogs, even in the long term. On the basis of these results, we speculate that central formation of granulation tissue does not occur under certain conditions, even when the tracheal epithelium is absent, although further details remain to be clarified.

\section{Conclusion}

We have developed a new type of Y-shaped tracheal prosthesis for carinal reconstruction and have demon- 
strated its efficacy and long-term safety in an experiment in dogs. We anticipate that, in the clinical setting, this new prosthesis will enable carinal reconstruction to be done more safely by reducing the tension at the anastomosis site.

\section{REFENCES}

1. Mulliken JB, Grillo HC. The limits of tracheal resection with primary anastomosis. J Thorac Cardiovasc Surg 1968;55:418-21.

2. Grillo HC. Circumferential resection and reconstruction of the mediastinal and cervical trachea. Ann Surg 1965;162:374-88.

3. Okumura N, Nakamura T, Natsume T, Tomihata K, Ikada Y, Shimizu Y. Experimental study on a new tracheal prosthesis made from collagen-conjugated mesh. J Thorac Cardiovasc Surg 1994;108:337-45.

4. Teramachi M, Okumura N, Nakamura T, et al. Intrathoracic tracheal reconstruction with a collagen-conjugated prosthesis: evaluation of the efficacy of omental wrapping. J Thorac Cardiovasc Surg 1997;113:701-11.

5. Grillo HC. Carinal reconstruction. Ann Thorac Surg 1982;34:356-73.

6. Theman TE, Kerr JH, Nelems JM, Pearson FG. Carinal resection: a report of two cases and a description of the anesthetic technique. J Thorac Cardiovasc Surg 1976;71:314-20.

7. Ishihara $T$, Ikeda $T$, Inoue $H$, Fukai S. Resection of cancer of lung and carina. J Thorac Cardiovasc Surg 1977;73:936-43.

8. Tsuchiya R, Goya T, Naruke T, Suemasu KJ. Resection of tracheal carina for lung cancer. J Thorac Cardiovasc Surg 1990;99:779-87.

9. Mathisen DJ, Grillo HC. Carinal resection for bronchogenic carcinoma. J Thorac Cardiovasc Surg 1991;102:16-23.

10. Sekine T, Nakamura T, Liu Y, Ueda H, Matsumoto K, Shimizu Y. A collagen-coated Y-shaped prosthesis for carinal replacement promotes regeneration of the tracheal epithelium. ASAIO J. (In press).

11. Pearson F, Henderson R, Gross A. Ginsberg R, Stone R. The reconstruction of circumferential tracheal defects with a porous prosthesis. J Thorac Cardiovasc Surg 1968;55:605-16.

12. Borrie J, Redshow N, Dobbinson T. Silastic tracheal bifurcation prosthesis with subterminal Dacron suture cuffs. J Thorac Cardiovasc Surg 1973;65:956-62.
13. Cull DL, Lally KP, Mair EA, Daidone M, Parsons DS. Tracheal reconstruction with polytetrafluoroethylene graft in dogs. Ann Thorac Surg 1990;50:899-901.

14. Neville WE, Bolanowski PJ, Koita GC. Clinical experience with the silicone tracheal prosthesis. J Thorac Cardiovasc Surg 1990;99:604-13.

15. Matsubara Y, Kosaba S, Ikeda S, et al: Experimental and clinical results of tracheal prosthesis. Kyobugeka 1990;43:368-74.

16. Toomes H, Mickisch G, Vogt-Moykopf I. Experiences with prosthetic reconstruction of the trachea and bifurcation. Thorax 1985;40:32-7.

17. Pearson FG, Todd TR, Cooper JD. Experience with primary neoplasms of the trachea and carina. $\mathbf{J}$ Thorac Cardiovasc Surg 1984;88:511-8

18. Shimizu Y, Tamura K, Kato H, Teramatsu T, Hino T. Study of artificial trachea using mesh. Jpn J Artif Organs 1983;12:486-9.

19. Poticha SM, Lewis J. Experimental replacement of the trachea. J Thorac Cardiovasc Surg 1966;52:61-7.

20. Jacobs J. Investigations into tracheal prosthetic reconstruction. Laryngoscope 1988;98:1239-45.

21. Morgan E, Lima O, Goldberg M, Ferdman A, Luk SK, Cooper JD. Successful revascularization of totally ischemic bronchial autografts with omental pedicle flaps in dogs. J Thorac Cardiovasc Surg 1982;84:204-10.

22. Ruoslahti E, Hayman EG, Pierschbacher MD. Extracellular matrices and cell adhesion. Arteriosclerosis 1985;5:581-94.

23. Rickard KA, Shoji S, Spurzem JR, Rennard SI. Attachment characteristics of bovine bronchial epithelial cells to extracellular matrix components. Am J Respir Cell Mol Biol 1991;4:440-8.

24. Davenport EA, Nettesheim P. Regulation of mucociliary differentiation of rat tracheal epithelial cells by type 1 collagen gel substratum. Am J Respir Cell Mol Biol 1996;14:19-26.

25. Takimoto N, Nakamura T, Yamamoto Y, Kiyotani T, Teramachi M, Shimizu Y. The experimental replacement of a cervical esophageal segment with an artificial prosthesis with the use of collagen matrix and a silicone stent. J Thorac Cardiovasc Surg 1998;116:98-106.

26. Natsume T, Ike O, Okada T, Takimoto N, Shimizu Y, Ikada Y. Porous collagen sponge for esophageal replacement. J Biomed Mater Res 1993;27:867-75.

27. Matsumoto K, Nakamura T, Shimizu Y, Ueda H, Sekine T, Yamamoto $Y$, et al. A novel surgical material made from collagen with high mechanical strength. ASAIO J 1999;45:288-92.

\section{Authoritative}

The Journal of Thoracic and Cardiovascular Surgery is the most frequently cited thoracic/cardiovascular surgery journal in the Science Citation Index. An article in JTCVS is sited on average almost twice as often as those in the closest cardiothoracic journal. 